\title{
CONSIDERAÇÕES ACERCA DA RELATIVIZAÇÃO DO CONTRATO DE LICENÇA DE USO DA IMAGEM DO ATLETA PROFISSIONAL DE FUTEBOL
}

\author{
Marcus Vinícius Costa Pinto \\ marcusfdf@gmail.com
}

\section{RESUMO}

O presente estudo busca tratar de tema extremamente atual mas, em contrapartida, deficiente em termos de contribuições doutrinárias: o direito desportivo. Mais especificamente, $\mathrm{o}$ objetivo é abordar, com maior especificidade, o problema da natureza jurídica do uso da imagem do atleta contratado. Tópico que, além de ter trazido notória controvérsia no mundo jurídico, a ponto de gerar um crise hermenêutica sobre uma série de institutos vinculados ao direito desportivo, importa, dependendo da conclusão a que se chega, em imensas transformações de ordem prática.

Palavras-chave: direito desportivo, uso da imagem, direito de arena

\begin{abstract}
This study seeks to address an extremely current topic but, in contrast, deficient in terms of doctrinal contributions: the sports Law. More specifically, the goal is to address, with greater specificity, the problem of the legal nature of the contracted athlete's image usage. Such topic, besides bringing on notable controversy in the legal world, generating a hermeneutic crisis on a series of institutes tied to sports Law, brings about immeasurable practical transformations, depending on the conclusion reached.
\end{abstract}

Keywords: Sports Law, image usage, arena right

\section{INTRODUÇÃO}

O futebol é um dos esportes mais praticados no mundo, e sua influência ultrapassa os limites do campo. Seus clubes e seleções representam muito mais do que meramente as associações e as federações ou confederações que os administram.

Alguns clubes, como o caso do Barcelona da Espanha, representante do povo catalão ou o Glasgow Rangers da Escócia, representante dos católicos de Dublin, são exemplos de proporções nunca antes vistas no esporte mundial, sendo possível até explicar certos atos de uma sociedade através dos acontecimentos futebolísticos. ${ }^{1}$

A importância social dos clubes, cumulada com a maior exposição na mídia, principalmente rádio e TV, e o melhor desempenho de alguns atletas fizeram destes profissionais verdadeiros heróis, capazes de reunir legiões de fãs ávidos a consumir qualquer produto relacionado ao ídolo.

\footnotetext{
${ }^{1}$ FOER, Franklin. Como o futebol explica o mundo: um olhar inesperado sobre a globalização; tradução Carlos Alberto Medeiros - Rio de Janeiro: Jorge Zahar, 2005. p 10.
} 
Empresas que antes estavam interessadas em associar suas marcas aos clubes, perceberam um novo mercado, ao vincular seus produtos aos jogadores, cujos resultados são de grande relevância.

Um dos primeiros casos no Brasil foi o de Leônidas da Silva, o Diamante Negro. Após ser considerado o melhor jogador da Copa do Mundo de 1934, negociou com a empresa Lacta a licença de uso de seu apelido para a criação de um novo chocolate. ${ }^{2}$

O caso do Diamante Negro demonstra que a existência da exploração da imagem do jogador de futebol não é recente no ordenamento jurídico pátrio, mas o tema se revestiu de especial relevância no final da década de noventa do século passado, porque os clubes de futebol passaram a usar deste instrumento jurídico de forma irrestrita.

Nas demandas, em regra, os reclamantes alegavam a fraude do contrato de trabalho por simulação, uma vez que o único motivo para existência do contrato de licença de uso da imagem seria a evasão fiscal e trabalhista. O reclamado, por sua vez, alegava a validade do pacto e tentava demonstrar a elisão fiscal.

O mais notório debate sobre o tema surgiu no início do século XXI quando o jogador Luiz Carlos Bombonato Goulart, conhecido como Luizão, processou o Sport Clube Corinthians Paulista. No caso em tela, o contrato de licença de uso da imagem do atleta foi considerado uma fraude ao contrato de trabalho, e o jogador foi liberado do para negociar com qualquer outro time.

O caso suscitou novos debates sobre o tema: o direito de imagem é uma fraude ao contrato de trabalho ou é uma forma de remuneração paga ao atleta por atrair novos consumidores?

\section{O CONTRATO DE TRABALHO DO JOGADOR DE FUTEBOL}

O contrato de trabalho é uma celebração entre empregado e empregador, para a prestação de um serviço, por prazo determinado ou indeterminado, em que o contratado se compromete a laborar para o contratante em troca de uma remuneração previamente estipulada e sob suas ordens. Neste prisma, a natureza jurídica do contrato de trabalho do jogador de futebol será a de um ato bilateral, privado, sinalagmático, formal, "intuitu personae", de trato sucessivo, oneroso e dotado de alteridade.

2 UNIVERSO On Line - UOL. Leônidas da Silva - Biografias. Disponível em: $<$ http://educacao.uol.com.br/biografias/ult1789u359.jhtm> Acesso em: 18 de Agosto de 2008. 
Essas são as principais características do contrato de trabalho e baseado nelas é que se deve construir uma relação segura e objetiva para identificar até que ponto se estende o vínculo trabalhista do atleta profissional de futebol com sua agremiação esportiva e começa o direito à exploração da imagem.

Ao estabelecer estes ditames cria a doutrina um modo de evitar a chamada simulação ao contrato de trabalho, conforme disposto no art. $9^{\circ}$ da CLT, pois determina objetivamente as condições e peculiaridades deste pacto.

Segundo alguns julgados o contrato de licença de uso da imagem entre atleta profissional e associação desportiva é um destes casos de simulação, devendo ser considerado, desde logo, parte integrante do salário do jogador e apresentando seus reflexos na relação de trabalho existente.

\begin{abstract}
ATLETA PROFISSIONAL - DIREITO DE IMAGEM X DIREITO DE ARENA. [...] A exploração da imagem do atleta, pactuada através do contrato de direito de imagem, decorre de sua condição pessoal, personalíssima (cuja inviolabilidade é assegurada constitucionalmente - art. $5^{\circ}, \mathrm{X}$ ) da "marca" do jogador, e que é cedida durante o contrato de trabalho ao empregador mediante contraprestação pecuniária. A imagem do atleta tem valoração pecuniária maior ou menor, conforme a relevância de sua posição perante o público e a sociedade, o que reverte em proveito do clube que explora a presença do profissional em seus quadros.

A criação de uma empresa jurídica pelo profissional não afasta o reconhecimento da natureza salarial dos valores pagos como retribuição pela cessão do direito de imagem do reclamante. Trata-se de artifício legal que não encontra amparo na legislação trabalhista, nos termos contidos no art. $9^{\circ}$ da CLT. ${ }^{3}$
\end{abstract}

Sobre este tema, o posicionamento jurisprudencial não é uníssono, porque alguns tribunais têm entendimento divergente do apresentado. Seus diversos aspectos serão abordados em capítulo posterior.

\title{
2 CONTRATO DE LICENÇA DE USO DA IMAGEM DO ATLETA PROFISSIONAL
}

No mundo do esporte, a exploração da imagem dos atletas objetivando agregar valor às marcas às quais eles prestam serviços é uma das principais fontes de renda das pessoas envolvidas no negócio.

\footnotetext{
${ }^{3}$ RECURSO Ordinário no 09996-2002-651-09-00-1; TRT - 9ª Região - 5a Turma; Relatora Juíza Eneida Caornel, j. 10 mar 2005.
} 
O melhor exemplo desta exploração vem da NBA - Nacional Basketball Association com o chamado "efeito Jordan", provocado pelo uso comercial da imagem do atleta Michael Jordan, que é considerado o maior jogador de basquete de todos os tempos ${ }^{4}$.

Ao final de quatorze temporadas, o chamado "efeito Jordan", movimentou aproximadamente 10 bilhões de dólares ${ }^{5}$ na economia americana, com os mais diversos produtos como uniformes, tênis, filmes, lanches, refrigerantes, perfumes, direitos de transmissão dos jogos do Chicago Bulls, franquia para a qual jogava, etc.

Existe no direito brasileiro, para remunerar situações análogas o contrato de licença de uso da imagem, de natureza civil, cuja existência "autoriza a vinculação da imagem do atleta

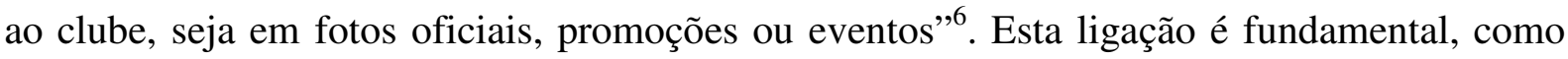
no caso acima, por ser o atleta uma figura pública e sua imagem atrair um grande número de consumidores.

O contrato de licença de uso da imagem tem algumas características especiais, pois trata de um dos direitos da personalidade, devendo zelar pela manutenção da liberdade da pessoa contratada e não podendo exigir grande sacrifício do mesmo.

Carlos Alberto Bittar conceitua de maneira clara e objetiva os ditames deste tipo de contrato:

[...] os contratos devem especificar a finalidade, as condições do uso, o tempo, o prazo e demais circunstâncias que compõem o conteúdo do negócio, interpretando-se restritivamente, ou seja, permanecendo no patrimônio do licenciante outros usos não enunciados por expresso. Não podem esses contratos - quando de exclusividade importar em cerceamento da liberdade da pessoa ou sacrifício longo de sua personalidade, sendo considerada nula, como cláusula potestativa, a avença que assim dispuser. $^{7}$

A finalidade exposta no conceito remete à idéia do objetivo do contrato: o porquê de efetuar um pagamento distinto a um atleta inserido no quadro de empregados da associação desportiva. Portanto, a razão do pacto é indenizar, da melhor forma, os jogadores de qualificação técnica superior e com maior potencial econômico para atrair consumidores, merecedor então de uma remuneração pela exploração comercial de um direito inerente à sua personalidade.

\footnotetext{
${ }^{4}$ O HOMEM de 10 Bilhões de Dólares. Revista Veja. São Paulo, n. 1.550, 10 jun. 1998. Disponível em: $<$ http://veja.abril.uol.com.br/100698/p_106.html>. Acessado em: 03 de junho de 2008.

5 O HOMEM de 10 Bilhões de Dólares. Revista Veja. São Paulo, n. 1.550, 10 jun. 1998. Disponível em: $<$ http://veja.abril.uol.com.br/100698/p_106.html>. Acessado em: 03 de junho de 2008.

${ }^{6}$ PEREIRA, Francisco Maurício. Novas perspectivas do contrato de trabalho do atleta profissional no Brasil. Monografia (Graduação em Direito)- Unesp, campus de Franca. Franca-São Paulo, Unesp, 2004, p 55.

${ }^{7}$ BITTAR, Carlos Alberto. Os direitos da personalidade. 2. ed. Rio de Janeiro: Forense, 2000. p 46
} 
A condição de uso é outro fundamento para o entendimento do contrato ora mencionado, porque estabelece até que ponto a empresa envolvida no negócio pode fazer uso da imagem do atleta, e em quais veículos de comunicação poderão ser vinculadas as campanhas publicitárias, sempre respeitando o princípio da dignidade da pessoa humana.

Quanto ao prazo do contrato, é importante salientar que o contrato de licença de uso da imagem possui algumas características especiais para descaracterizar a malfadada simulação do contrato de trabalho.

A primeira característica está disposta no art. $28, \S 7^{\circ}$ da Lei $9.615 / 98$, acrescido pela Lei 10.672/03, que veda a outorga de poderes, mediante instrumento procuratório público ou particular, relacionados a vínculo desportivo e uso de imagem de atletas profissionais em prazo superior a um ano ${ }^{8}$. Importante observar o critério para renovação o qual não deve ultrapassar o limite legalmente disposto para o contrato.

Alguns doutrinadores, como Felipe Legrazie Ezabela, entendem que apesar da Lei Pelé ser omissa no tocante à renovação do contrato de licença de uso da imagem, para não caracterizar fraude, este terá duração máxima de um ano, renovável por apenas mais um período de igual duração. Fora destes parâmetros estaria caracterizada a evasão fiscal. ${ }^{9}$

A segunda característica para evitar a simulação é a utilização desta forma de contraprestação apenas enquanto a imagem do atleta for explorada pela associação esportiva, não sendo devido o pagamento em outros momentos.Nesta hipótese, se a agremiação faz uso comercial da imagem dos seus atletas em campanhas publicitárias com o intuito de aumentar seu lucro, é no período de validade destas ações que deve o atleta receber pelos trabalhos prestados além da esfera futebolista.

Caso a exploração da imagem do atleta não seja mais comercialmente interessante, para o clube ou para o jogador, basta a simples extinção do contrato, por qualquer meio em Direito admitido, para que a licença de uso da imagem deixe de existir sem necessariamente acarretar o fim do contrato de trabalho entre associação desportiva e atleta.

As demais circunstâncias conceituadas por Bittar remetem a idéia de um grupo de características especiais inerentes ao caso concreto, como o valor atribuído a esta licença de uso da imagem, a outorga futura para exploração em alguns tipos de mídia ou para associação a determinados produtos, etc.

\footnotetext{
${ }^{8}$ LEI 9.615 de 24 de março de 1998 - Lei Pelé. Artigo 28, parágrafo $7^{\circ}$.

${ }^{9}$ EZABELA, Felipe Legrazie. O Direito Desportivo e a Imagem do Atleta. São Paulo: IOB Thompson, $2006 \mathrm{p}$ 116.
} 
Por todas essas especificidades, o contrato de licença de uso da imagem tem natureza civil e não trabalhista como pregam alguns tribunais em recentes decisões.

Neste sentido, julgou o Juiz Ricardo Luiz Tavares Gehling da $4^{\text {a }}$ Turma do Tribunal Regional do Trabalho (TRT) da 4 a Região:

[...] o pagamento feito ao atleta, pelo uso de sua imagem, constitui verba de natureza civil relacionada ao contrato de trabalho - e por este motivo compete a esta Justiça apreciar a matéria. Não se trata de contraprestação pelos serviços prestados e por isso não tem caráter remuneratório. É, sim, uma indenização que a entidade esportiva paga ao atleta pela exposição de sua imagem. ${ }^{10}$

O magistrado Darcy Carlos Mahle, também do Rio Grande do Sul, decidiu de maneira análoga:

[...] Os valores pagos pelo uso da imagem do jogador de futebol, quando ajustados por meio de contrato civil, firmado por pessoa jurídica que tem como um dos participantes o próprio atleta, revestem-se de caráter indenizatório, afastando a possibilidade de repercussão em qualquer direito trabalhista". ${ }^{11}$

Os julgados expostos permitem o entendimento da natureza jurídica destes contratos e apresentam a tese da ausência de reflexos do contrato civil no âmbito trabalhista.

Ao proferir tal acórdão, a $4^{\mathrm{a}}$ Turma do TRT, toma posição no sentido de defender a existência de uma indenização de natureza civil relacionada ao contrato de trabalho, mas não trabalhista.

O posicionamento jurisprudencial acima contempla uma nova realidade das atividades esportivas, porque permite ao atleta ser remunerado por licenciar sua imagem para exploração do clube. Ao pactuar este acordo o jogador autoriza o uso de sua marca pessoal para aumentar o público consumidor dos produtos de seu empregador e maximiza seus lucros. O clube, em contrapartida pode explorar a imagem do futebolista em qualquer atividade de marketing, construindo assim uma relação mais próxima com o torcedor que se identifica com o ídolo.

\section{DIFERENÇAS ENTRE O CONTRATO DE TRABALHO E O CONTRATO DE LICENÇA DE USO DA IMAGEM DO ATLETA}

Por sua vez, o contrato de licença de uso da imagem do atleta também possui características idênticas as do contrato de trabalho do jogador de futebol profissional, diferenciando apenas a natureza jurídica que é civil, sendo regido por normas contidas neste

\footnotetext{
${ }^{10}$ RECURSO Ordinário no 00977-2002-403-04-00-7-RS - TRT - 4 ${ }^{\mathrm{a}}$ Região - 4 ${ }^{\mathrm{a}}$ Turma; Relator: Juiz Ricardo Luiz Tavares Gehling; j. 25/05/2004

${ }^{11}$ RECURSO Ordinário no 00874-2001-022-04-00-9 - TRT - 4 Região - 4 ${ }^{\text {a }}$ Turma; Relator: Juiz Darcy Carlos Mahle; j. 1\% $\% 4 / 2004$.
} 
ramo do Direito e pode ser firmado entre o clube empregador e uma pessoa jurídica procuradora do jogador.

Outras diferenças destes contratos são apresentadas por Álvaro de Melo Filho, em seu livro Direito Desportivo - Aspectos Teóricos e Práticos, e facilitam o entendimento sobre o assunto:

\section{Contrato de Trabalho Desportivo}
a) é de natureza civil;
b) seu valor é considerado para quantificar a cláusula penal desportiva;
c) deve ser registrado na entidade nacional de administração do desporto;
d) vincula atleta/clube (pessoa física/jurídica) envolvendo duas partes;
e) seu quantum é base de incidência para contribuição do INSS, FGTS, férias e $13^{\circ}$ salário;
f) sua cláusula penal submete-se a redutores fixados na legislação desportiva;
g) prazo de duração não pode ser superior a 5 (cinco) anos;
h) valor da cláusula penal pode exceder ao da obrigação principal;
i) $51 \%$ é o montante de obrigações trabalhistas, sociais, fiscais e previdenciárias;
j) envolve força de trabalho.

\section{Contrato de Licença de Uso de Imagem Desportiva}

a) é de natureza civil;

b) seu valor não é considerado para quantificar a cláusula penal do contrato de trabalho desportivo;

c) não é registrado na entidade nacional de administração do desporto;

d) vincula atleta/clube/pessoa jurídica do atleta envolvendo três partes;

e) não gera incidência de FGTS, férias e $13^{\circ}$ salário;

f) não há redutores aplicáveis à cláusula penal;

g) prazo de duração pode ser superior a 5 (cinco) anos;

h) $17,5 \%$ é o montante de obrigação trabalhistas, sociais, fiscais e previdenciárias;

i) envolve utilização da imagem. ${ }^{12}$

${ }^{12}$ MELLO Filho, Álvaro. Direito desportivo: aspectos teóricos e práticos. São Paulo: IOB Thomson, 2006. p 135 . 
A exposição destes elementos diferencia os contratos e suscita um dos principais debates sobre o tema: seria o contrato de licença de uso da imagem desportiva uma evasão ou uma elisão fiscal?

Para os filiados à teoria da evasão, seria o contrato de licença de uso da imagem uma forma de burlar a legislação trabalhista e tributária, sendo necessária a anulação dos atos praticados sob o manto deste pacto. A outra corrente apresenta a tese deste contrato ser uma forma de elisão fiscal, portanto seria lícita a sua existência e válidos todos os seus efeitos.

O problema da evasão e/ou elisão fiscal não é exclusivo do Brasil. Alguns países da Europa, como França e Espanha, estipularam percentuais máximos para os valores auferidos a título de direito de imagem, evitando assim prolongados debates sobre o tema.

A legislação espanhola limitou o valor do contrato de licença de uso da imagem em $15 \%$ do efetivo rendimento salarial do atleta, devido principalmente à difícil aferição, sobretudo em face de elementos intangíveis e subjetivos, possibilitando assim um critério de fácil aplicação e controle. Já a lei francesa limitou em $40 \%$ a elisão fiscal do contrato de licença de uso da imagem entre atleta e clubes. ${ }^{13}$

O contrato de licença de uso da imagem desportiva é uma forma de elisão fiscal, pois não existe ilegalidade aparente no contrato celebrado entre agentes capazes, com valores regulados pela lei de mercado e tutelado pelo constituinte originário.

Para o Direito Desportivo brasileiro é de grande valia o legislador impor limites para a elisão fiscal do contrato de licença de uso da imagem desportiva evitando "manobras" e contratos de "fachadas", seguindo assim o exemplo da França e da Espanha.

O estipulado na legislação francesa, de até $40 \%$ do valor do salário, é norteador interessante, pois possibilita uma melhor remuneração ao atleta que agrega maior valor à marca do clube. A legislação espanhola, por sua vez, apesar de estipular um percentual (15\% do salário), não permite grande rentabilidade ao jogador que, necessariamente, precisa de um contrato de trabalho vultoso para auferir quantia significativa a título de licença de uso da imagem.

O surgimento de uma norma reguladora para fixar o limite da licença de uso da imagem entre atleta e clube pode ser interpretado por aqueles contrários à esta inovação, como um cerceamento da livre iniciativa, uma vez que os contratantes não podem

\footnotetext{
${ }^{13}$ MELLO Filho, Álvaro. Direito desportivo: aspectos teóricos e práticos. São Paulo: IOB Thomson, 2006. p 134.
} 
deliberadamente firmar os valores relativos à indenização da exploração da imagem do jogador, sendo desde logo inconstitucional tal dispositivo por ferir o art $1^{\mathrm{o}}$, IV da Lei Maior ${ }^{14}$. Posicionamento distinto, mas também com escopo constitucional no artigo $1^{\circ}$, IV da Constituição Federal, é o que defende a norma para evitar práticas simulatórias lesivas ao disposto na legislação tributária, previdenciária e trabalhista, uma vez que a Carta Magna protege os valores sociais do trabalho.

A simulação existente no contrato de licença de uso da imagem só seria resolvida se a legislação delimitasse a atuação dos particulares para evitar atos lesivos ao trabalhador e à sociedade. Por mais que a livre iniciativa possa ser cerceada, o fator discriminante é justificável, pois a segurança jurídica criada com o dispositivo legal permitiria mecanismos transparentes para o uso e a indenização deste direito da personalidade.

\section{AS DIFERENÇAS ENTRE DIREITO DE IMAGEM E DIREITO DE ARENA}

As diferenças entre o contrato de licença de uso da imagem do atleta e o direito de arena são objeto de grande discórdia no mundo jusdesportivo, pois é entendimento de parte da doutrina e de alguns tribunais que os dois institutos seriam semelhantes.

O Tribunal Regional do Trabalho da $3^{\mathrm{a}}$ Região, na sua $7^{\mathrm{a}}$ Turma, ao julgar Recurso Ordinário do Clube Atlético Mineiro contra o jogador Cícero João de Cezare, assim decidiu sobre o tema:

[...] se o texto legal não faz qualquer menção a direito de arena, deduz-se disto que o direito de arena e direito de imagem não são figuras distintas, havendo similaridade entre ambas. A doutrina apenas adotou outra terminologia não prevista na lei. E, se o direito de imagem e direito de arena são uma coisa só, prevista em lei específica do atleta profissional de futebol, tem-se que se trata de uma verba eminentemente trabalhista. ${ }^{15}$

Domingos Sávio Zainaghi acompanha a $7^{a}$ turma do TRT Mineiro:

[...] o direito à imagem já está previsto na Lei n. 9.615/98, ou seja, é o direito de arena, o qual consiste no pagamento de $20 \%$ do valor recebido pelos clubes a ser dividido entre os atletas que participaram da partida. ${ }^{16}$

A controvérsia é latente, pois dentro do próprio TRT da $3^{\mathrm{a}}$ região a $8^{\mathrm{a}}$ turma tem posicionamento diverso, em caso análogo envolvendo o mesmo Clube Atlético Mineiro e o atleta Edgar de Matos Albino:

\footnotetext{
${ }^{14}$ VADE Mecum RT - 2. ed. rev. ampl. e atual. São Paulo: Editora Revista dos Tribunais, 2008. p 29

${ }^{15}$ RECURSO Ordinário n ${ }^{\circ}$ 00960-2004-016-03-00-0-RO - TRT - $3^{\mathrm{a}}$ Região - $7^{\mathrm{a}}$ Turma; Relator: Juiz Rodrigo Ribeiro Bueno; j. 13 set 2005.

${ }^{16}$ ZAINAGHI, Domingos Sávio. Nova legislação desportiva - aspectos trabalhistas. São Paulo: LTr, 2001, p 30
} 
Portanto, arena é o local onde ocorre evento esportivo, estabelecendo a legislação uma percentagem mínima do valor relativo à negociação do direito de transmissão do espetáculo, a ser distribuída aos seus atores, os atletas.

Considerando a excessiva divulgação da imagem dos desportistas pelos meios de comunicação em geral e o direito fundamental previsto no inciso XXVIII da CF/88, nada obsta, ainda, a comercialização pelo atleta profissional de sua imagem, não havendo óbice legal à constituição de empresa com esse fim e à celebração de contrato com a entidade de prática desportiva envolvendo a cessão do direito de uso de sua imagem. ${ }^{17}$

O Superior Tribunal de Justiça tem entendimento análogo ao da $8^{\text {a }}$ Turma do TRT/MG ao assim interpretar as limitações do Direito de Arena:

Direito de Arena. Limitação. Direito de Imagem. Divergência jurisprudencial não configurada.

I - O direito de arena é uma exceção ao direito de imagem e deve ser interpretado restritivamente. A utilização com intuito comercial da imagem do atleta fora do contexto do evento esportivo não está por ele autorizada. Dever de indenizar que se impõe. ${ }^{18}$

A posição do STJ e da $8^{a}$ Turma do TRT/MG é a de Álvaro de Melo Filho, que sustenta:

O direito de arena é a faculdade outorgada por lei às entidades desportivas para negociar a imagem coletiva do espetáculo de que participem [...] Já o direito de imagem é personalíssimo do atleta para utilizar a sua popularidade, fora da situação do espetáculo desportivo, com vistas a angariar patrocinadores e consumidores, vender produtos, divulgar marcas por meio de outras formas que não se categorizam como vínculo de subordinação ou de dependência atrelada a contrato de trabalho desportivo $[\ldots]^{19}$

A segunda teoria parece contemplar de maneira objetiva a nova realidade do esporte no mundo. Cada vez mais os atletas são tratados como modelos e suas imagens são associadas aos mais diversos produtos como chicletes, desodorantes, álbum de figurinhas, celulares, produtos financeiros. Em alguns casos, os superatletas fazem mais propagandas que modelos como Gisele Bündchen, que vive da própria imagem. ${ }^{20}$

A imagem do jogador é outra possibilidade de obtenção de renda pelo trabalhador e uma forma de reduzir a mais valia presente na relação clube-atleta. Se considerar o direito de imagem como um direito de arena, o empregador poderá explorar indiscriminadamente a imagem-atributo do seu empregado sem indenizá-lo por tal ato.

\footnotetext{
${ }^{17}$ RECURSO Ordinário no 009960-2004-016-03-00-0-RO - TRT - 3 ${ }^{\text {a }}$ Região - 7 $7^{\text {a }}$ Turma; Relator: Juiz Rodrigo Ribeiro Bueno; j. 13 set 2005.

${ }^{18}$ STJ - $3^{\text {a }}$ Turma - AI 141987-SP, Relator Ministro Eduardo Ribeiro, j. 15/12/1997

${ }^{19}$ MELLO Filho, Álvaro. Direito Desportivo: Aspectos teóricos e práticos. São Paulo: IOB Thompson, 2006 p.136.

${ }^{20}$ PACHECO, Paula. Pão, circo e grana. Revista Carta Capital n 391 Ano XII. 3 de Maio de 2006. p 15
} 
O mesmo Álvaro de Melo Filho, em sua obra Direito Desportivo: aspectos teóricos e práticos., na página 136, apresenta outras diferenças entre os dois direitos, fundamentais para o entendimento das peculiaridades de cada um dos institutos:

\section{Direito de Arena}

a) decorre da lei;

b) é coletivamente usufruído;

c) não se reveste de periodicidade;

d) ocorre dentro do contexto do evento desportivo transmitido;

e) tem natureza salarial;

f) deve ser limitado a $20 \%$ do que recebe o clube, valor este rateado entre todos os atletas participantes do evento.

\section{Direito de Imagem}

a) decorre do contrato;

b) é individualmente usufruído;

c) normalmente reveste-se de periodicidade;

d) ocorre fora do contesto do evento desportivo transmitido;

e) não tem natureza salarial;

f) gera $100 \%$ para o atleta cedente do uso da imagem, sem rateio para os demais atletas.

O direito de arena, no tocante ao atleta, consiste na participação individual em obra coletiva, constitucionalmente defendida; entretanto a negociação é do empregador, que deve pagar o empregado com o mesmo zelo da participação nos lucros da empresa. Já o direito de imagem é um direito da personalidade, de titularidade do jogador e o clube pode negociar com este o seu uso, assim como qualquer outra empresa interessada em associar a figura do esportista com a sua marca, este direito também é expresso na Carta Magna (art.5 ${ }^{\circ}$,inc.X da $\mathrm{CF})$.

Portanto os dois direitos, ora mencionados, são distintos, possuem características próprias e tratam de assuntos próximos, não idênticos. O direito de arena pode ser interpretado como uma forma de "gorjeta" e possui natureza trabalhista, enquanto o direito de imagem compõe o rol de direitos da personalidade e é de natureza civil.

\section{CONCLUSÃO}


As incertezas sobre a conceituação e delimitação dos contratos de trabalho, imagem e a participação a título de direito de arena resulta na crise hermenêutica sobre a legalidade e coexistência destes pactos. Os tribunais não sedimentam um entendimento jurisprudencial por não conceituarem de maneira objetiva os ditames de cada instituto.

A resposta para esta crise interpretativa parte, necessariamente, da aplicação da isonomia material. As desigualdades devem ser preponderantes na análise do caso concreto, pois os atletas de alta performance têm o direito de negociar com os clubes uma indenização, porque atraem um novo público e às vezes até um novo mercado. Enquanto jogadores de desempenho médio ou baixo não acrescentam ganhos, além daqueles estritamente vinculados à sua atividade em campo, não podendo assim postular tal direito. A relativização do contrato de licença de uso da imagem do atleta profissional de futebol consiste na aplicação deste princípio às relações jurídicas pertinentes.

Jogadores que atraem um maior número de torcedores e empresas merecem receber esta contraprestação, e o clube deve pactuar para melhor explorar o potencial econômico de seus colaboradores. Desta forma, qualquer campanha publicitária para atrair sócios, vender produtos licenciados ou atrair convênios com patrocinadores será devidamente regulada e a imagem do futebolista será devidamente indenizada.

Outros podem entender que o direito de arena atende à questão publicitária envolvendo clube e jogador, mas, como devidamente foi apresentado, se restringe as transmissões esportivas e não da exposição extra-campo. O direito de imagem tutela de maneira mais completa as novas necessidades da relação clube-atleta, porque se refere aos assuntos "fora das quatro linhas", como as formas de maximizar os lucros dos envolvidos.

A interpretação de simulação do contrato de trabalho em qualquer contrato de licença de uso da imagem é uma perigosa forma de aplicação do direito, uma vez que, como já demonstrado no "efeito Jordan", existem jogadores merecedores de indenização por serviços prestados, além do labor pactuado.

A existência de alguns casos de fraude ao contrato de trabalho, através do contrato de licença de uso de imagem é inegável, como alguns julgados apresentados neste trabalho, mas considerar todos os pactos como ilegais é promover um retrocesso no direito e negar a existência e a importância deste esporte e dos jogadores na sociedade.

A proposta aqui apresentada de relativizar o contrato de licença de uso da imagem do atleta constitui um progresso no mundo jusdesportivo, consoante a nova realidade do esporte, 
sendo, pois, o mais justo e adequado mecanismo remuneratório nesses casos. Os atletas podem obter maior fonte de renda e os clubes maximizarem os meios de obtenção de dividendos.

Os lucros e os vencimentos serão maximizados, além do possível aumento da renda com a venda de produtos, com a elisão fiscal e trabalhista, pois ao firmar um contrato de natureza civil, as partes terão redução na carga tributária e nos direitos trabalhistas (o jogador deixa de pagar $51 \%$ e passa a desembolsar 17,5\%) usando de meios permitidos pela legislação.

A relativização do contrato de licença de uso da imagem permite, portanto, para clubes e atletas a redução de impostos sem praticar delitos; e ao magistrado, a faculdade de não se sujeitar à aplicação da letra fria da lei, podendo, assim, fazer uso dos princípios jurídicos para obter um resultado equânime, em prol da resolução mais benéfica aos interesses conflitantes.

\section{REFERÊNCIAS}

BITTAR, Carlos Alberto. Os direitos da personalidade. 2. ed. Rio de Janeiro: Forense, 2000. EZABELA, Felipe Legrazie. O direito desportivo e a imagem do atleta. São Paulo: IOB Thompson, 2006.

FOER, Franklin. Como o futebol explica o mundo: um olhar inesperado sobre a globalização. Tradução Calos Alberto Med eiros. Rio de Janeiro: Jorge Zahar, 2005.

MELO FILHO, Álvaro. Direito desportivo: aspectos teóricos e práticos. São Paulo: IOB Thompson, 2006.

O HOMEM de 10 bilhões de dólares. Revista Veja. São Paulo, n. 1.550, 10 jun. 1998. Veja. Disponível em: <http://veja.abril.uol.com.br/100698/p_106.html>.Acessado em: 03 jun. 2008. PACHECO, Paula. Pão, circo e grana. Revista Carta Capital, n. 391 Ano XII. 3 maio 2006. PEREIRA, Francisco Maurício. Novas perspectivas do contrato de trabalho do atleta profissional no Brasil. Monografia (Graduação em Direito)- Unesp, campus de Franca. Franca-São Paulo, Unesp, 2004.

UNIVERSO On Line - UOL. Leônidas da Silva. Biografias. Disponível em: <http://educacao.uol.com.br/biografias/ult1789u359.jhtm>. Acesso em: 18 ago. 2008.

ZAINAGHI, Domingos Sávio. Nova legislação desportiva: aspectos trabalhistas. São Paulo: LTr, 2001. 